\title{
Tensile Shear Strength Improvement of 18-8 Stainless Steel/CFRP Joint Irradiated by Electron Beam Prior to Lamination Assembly and Hot-Pressing
}

\author{
Akiko Minegishi $^{1, *}$, Takumi Okada ${ }^{1}$, Masae Kanda ${ }^{1,2}$, Michael C. Faudree ${ }^{2}$ and Yoshitake Nishi ${ }^{1,2}$ \\ ${ }^{1}$ Graduate School of Engineering, Tokai University, Hiratsuka 259-1292, Japan \\ ${ }^{2}$ Department of Materials Science, Tokai University, Hiratsuka 259-1292, Japan
}

\begin{abstract}
Adhesive 2-layer lamination joints of 18 mass $\% \mathrm{Cr}-8$ mass $\% \mathrm{Ni}$ austenite stainless steel and carbon fiber reinforced polymer (18-8/CFRP joint) were prepared using a new adhesion method consisting of applying low dose of 0.13 MGy of homogeneous low energy electron beam irradiation (HLEBI) to connecting surfaces of the 18-8 and CFRP prior to lamination assembly and hot-pressing in vacuum below $1 \mathrm{~Pa}$ for $2 \mathrm{~h}$ at $401 \pm 0.5 \mathrm{~K}$. Although untreated 18-8/CFRP joint exhibited decent adhesion by hot-pressing, application of $0.13 \mathrm{MGy}$ HLEBI dose apparently improved the tensile shear strength, $\tau_{\mathrm{B}}$ of the 18-8/CFRP joint $58 \%$ at median accumulative probability $\left(P_{\mathrm{B}}=0.50\right)$ from 4.0 to $6.3 \mathrm{MPa}$. In addition, applying HLEBI from 0.13 and $0.30 \mathrm{MGy}$ was found to enhance the $\tau_{\mathrm{B}}$ at all $P_{\mathrm{B}}$. Based on the 3-parameter Weibull equation, the statistically lowest $\tau_{\mathrm{B}}$ value at $P_{\mathrm{B}}=0\left(\tau_{\mathrm{s}}\right)$ was increased from zero to $4.39 \mathrm{MPa}$ by the $0.13 \mathrm{MGy}$ HLEBI. XPS (X-ray photoelectron spectrometry) measurements detected carbon on the shear-fractured 18-8 interface indicating the residual epoxy adhered well to the $18-8$ by the HLEBI. This is probably a result of adhesion force of 18-8/CFRP being made stronger than the cohesive force of epoxy polymer in the CFRP itself. Since HLEBI cuts the chemical bonds and generates active terminated atoms with dangling bonds in epoxy polymer and passive film on $18-8$, the increased adhesion force in the 18-8/CFRP joint can be explained by the chemical bonding and coulomb attractive forces thus induced at the interface. Since the experimental data shows the optimum HLEBI dose is about $0.13 \mathrm{MGy}$, above which at $0.30 \mathrm{MGy}$ the $\tau_{\mathrm{B}}$ begins to drop off, carefulness in optimization is highly recommended when applying in industry to insure safety. [doi:10.2320/matertrans.M2015105]
\end{abstract}

(Received March 12, 2015; Accepted May 8, 2015; Published June 26, 2015)

Keywords: joint, stainless steel, carbon fiber reinforced epoxy polymer (CFRP), shear strength, shear strain, electron beam, adhesion

\section{Introduction}

Techniques to increase the strength of metal/composite joints are highly sought after. Austenite stainless steel (18-8) joined with CFRP for structural applications has been widely utilized in the aerospace, automotive and shipbuilding industries, along with various day-to-day items. Carbon fiber reinforced epoxy polymer (CFRP) with its high strength to weight ratio along with $18-8$ with its high heat-resistance, high corrosion resistance and high tensile strength have been widely utilized for bullet train vehicles, automobiles, ships and airplanes. ${ }^{1,2)}$

It is always important to develop a joint with maximum safety enhancement adding minimal weight to the structure for low energy consumption with concern for the environment. However, the two major methods of joining different materials: mechanical fastening and adhesive bonding although having their advantages, possess their shortcomings. ${ }^{3)}$ Mechanical fastening uses bolts and rivets, whereas adhesive bonding methods range from applying an adhesive, brazing or welding.

Advantages of fasteners are simple processing, high joining strength, and small scatter in the data. However, disadvantages include increase in weight due to the fasteners and low sealing performance. Moreover, the bolt holes decrease the crosssectional area and can act as stress concentrators. It is reported drilling holes in FRP laminate composites result in breakage of the reinforcing fibers, peeling of the top plies at hole entry, resin degradation at the hole wall, and delamination of the bottom plies of the laminates. ${ }^{4,5)}$ The resulting damage can result in generation of fatigue cracks during fatigue. ${ }^{\text {) }}$

For adhesive bonding methods, advantages are complete sealing effect, parts are lighter since fasteners are not used,

*Graduate Student, Tokai University

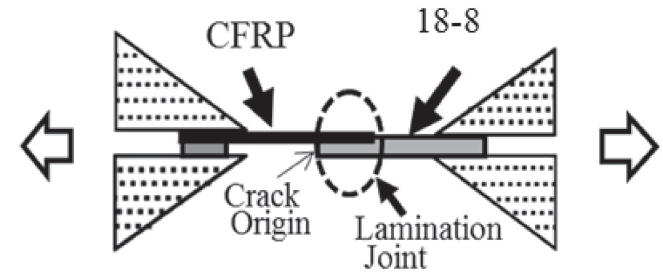

Fig. 1 Schematic drawing of shear testing sample.

hence no stress concentration due to the bolt hole and no damage due to drilling, therefore they typically exhibit higher fatigue strength than bolted joints. ${ }^{6)}$ Conversely, disadvantages include adhesion selection is difficult for joints of different materials, additional steps of degreasing and etching the adhering surfaces are needed to obtain high adhesion strength. ${ }^{7)}$ Moreover, chemically treated adhesive joints have the disadvantage of degradation after a few hours by oxidation decreasing bonding strength. ${ }^{7)}$ Due to these limitations, high strength adhesive joints are difficult to attain.

However, this research shows a joint of 18-8 stainless steel and CFRP (Fig. 1) was achieved without the use of fasteners, chemical treatment, or external adhesive by a new adhesion method; a double-step treatment consisting of: (1) applying low dose of homogeneous low energy electron beam irradiation (HLEBI) to connecting surfaces of the CFRP and $18-8$, respectively prior to, (2) lamination assembly and hot-pressing. The HLEBI is a quick and safe adhesion method applied in very short bursts of $\sim 0.20 \mathrm{~s}$ to laminate 18-8 with epoxy CFRP without adhesive or heating the materials.

HLEBI has a successful track record for improving many materials. $^{8-17)}$ HLEBI is reported to improve the mist resistance and wetting of materials, ${ }^{8-11)}$ and increases 
polymer adhering to fibers raising impact strength in GFRP. ${ }^{12,13)}$ HLEBI has been found to successfully create or enhance adhesive strength of difficult to bond metal-polymer joints. For $\mathrm{Al}$ and PU (polyurethane) when untreated could not be joined by hot-pressing, applying HLEBI of 0.13 and $0.22 \mathrm{MGy}$ is reported to create the $\mathrm{Al} / \mathrm{PU}$ joint generating adhesive peeling forces $\left({ }^{\circ} F_{\mathrm{p}}\right)$ of 29 and $34 \mathrm{Nm}^{-1}$, respectively at median-rank accumulative peeling probability $P_{\mathrm{p}}=0.50 .{ }^{14)}$ Moreover, in $\mathrm{Cu} / \mathrm{PU}$ joint applying 0.04 $0.22 \mathrm{MGy}$ HLEBI is reported to have increased the ${ }^{\circ} F_{\mathrm{p}}$ at $P_{\mathrm{p}}=0.50$ three to four-fold from $<10$ to $30-40 \mathrm{~N} \mathrm{~m}^{-1}$. ${ }^{15}$ )

HLEBI is surface treatment that cuts the chemical bonds at the polymer surface and generates active terminated atoms with dangling bonds in polymers. ${ }^{16)}$ The dangling bonds act as reaction sites for bonding polymer surfaces with metals. Total treatment time of HLEBI application is only a few seconds. Therefore, we demonstrate by applying 0.13 MGy-HLEBI to both the $18-8$ and CFRP prior to lamination assembly and hot-pressing tensile adhesive shear strength $\left(\tau_{\mathrm{B}}\right)$ and its strain, $\varepsilon_{\mathrm{B}}$ of the $18-8 / \mathrm{CFRP}$ joint is significantly boosted $\sim 50 \%$ and $\sim 75 \%$, respectively over the untreated.

\section{Experimental Procedure}

\subsection{Preparation of 18-8/CFRP}

The joints were constructed from their separate components of: (1) 18 mass \% Cr-8 mass\% Ni austenite (18-8) stainless steel Japanese Industrial Standard SUS304 with dimensions $[10 \mathrm{~mm} \times 40 \mathrm{~mm} \times 2.0 \mathrm{~mm}]$, Taiho trading Co., LTD.); and (2) cured CFRP (carbon fiber reinforced polymer); TR3110-331MP epoxy/CF, Mitsubishi Rayon Ltd., Tokyo) with dimensions $[10 \mathrm{~mm} \times 40 \mathrm{~mm} \times 0.25 \mathrm{~mm}]$ being 1 ply $0.25 \mathrm{~mm}$ in thickness.

The cured CFRP was a carbon fiber cross-weave whose calculated volume was therefore $100 \mathrm{~mm}^{3}$ with adhesive area $\left(10 \times 10=100 \mathrm{~mm}^{2}\right)$ for tensile shear test. In the cured CFRP sheet, volume fraction, $V_{\mathrm{f}}$ of carbon fiber was $60 \%$.

Preparation steps of the 18-8/CFRP joint samples were as follows: As Step 1, the 18-8 and cured CFRP were cut to size. As Step 2, the novel part of the process: homogeneous low-voltage electron beam (HLEBI) treatment (Section 2.2) was applied to the connecting surfaces of the 18-8 and CFRP. As Step 3, the CFRP and 18-8 were assembled. As Step 4, the $18-8 /$ CFRP assembly was inserted into a hot-pressing under vacuum below $1 \mathrm{~Pa}$ for $2 \mathrm{~h}$ at $401 \pm 0.5 \mathrm{~K}$ to cure the CFRP to adhere to the $18-8$ producing the laminated joint samples. No fasteners or external adhesives were applied: the cured epoxy enhanced by the HLEBI acts as the adhesive to the $18-8$.

\subsection{Homogeneous low voltage electron beam irradiation (HLEBI)}

The connecting surfaces of 18-8 and CFRP sheets were homogeneously irradiated by an electron-curtain processor (Type CB175/15/180L, Energy Science Inc., Woburn, MA, Iwasaki Electric Group Co., Ltd., Tokyo). ${ }^{18-22)}$ The samples were homogeneously irradiated with an electron beam through a titanium window attached to a $24 \mathrm{~cm}$-diameter vacuum chamber. A tungsten filament in a vacuum was used to generate the electron beam with an electric voltage of $0.17 \mathrm{MeV}$ and an irradiating current of $2.0 \mathrm{~mA}$. To prevent oxidation, the samples were kept in a $\mathrm{N}_{2}$ atmosphere of $0.10 \mathrm{MPa}$ with a residual $\mathrm{O}_{2}$ concentration of less than $0.040 \%$. The flow rate of the $\mathrm{N}_{2}$ was $1.5 \mathrm{~L} / \mathrm{s}$.

Given the densities $(\rho)$ are $7.9 \mathrm{~g} \cdot \mathrm{cm}^{-3}$ for the $18-8$ stainless steel; $1.76 \mathrm{~g} \cdot \mathrm{cm}^{-3}$ for carbon fiber; and $1.20 \mathrm{~g} \cdot \mathrm{cm}^{-3}$ for cured epoxy, the penetration depth $\left(D_{\text {th }}\right)$ values of $0.028 \mathrm{~mm}$ for $18-8$; $0.126 \mathrm{~mm}$ for carbon fiber; and $0.185 \mathrm{~mm}$ for epoxy, respectively were estimated by assumptions of Christenhusz and Reimer. ${ }^{23)}$ The $D_{\text {th }}$ of $0.027 \mathrm{~mm}$ for $18-8$; and $0.144 \mathrm{~mm}$ for the $60 \%$ carbon fiber $V_{\mathrm{f}} \mathrm{CFRP}$ are considered sufficient for action of dangling bonds to increase adhesion of the 188/CFRP interface.

\subsection{Tensile shear strength, its strain and fracture strain}

Tensile shear strength tests were performed by an Instron type tensile machine at a constant strain rate of $1 \mathrm{~mm} / \mathrm{min}$ on the samples as illustrated in Fig. 1 where the joint was pulled in tension, a shim being added with the thin CFRP sheet in the grips. The tensile shear strength $(\tau)$-strain $(\varepsilon)$ curves were obtained where the tensile shear strength $\left(\tau_{\mathrm{B}}\right)$ is defined as the maximum shear stress.

The cumulative probability $(P)$ by the median-rank method $^{24)}$ often employed in quality control (QC) is one of the widely used and convenient ways to analyze mechanical probabilities of adhesive strength, ${ }^{19)}$ adhesive peeling resistance, ${ }^{25)}$ along with other mechanical properties. ${ }^{12,26-31)}$ Accumulative probabilities $\left(P: P_{\mathrm{i}}, P_{\max }, P_{\mathrm{B}}, P_{\mathrm{S} \varepsilon}, P_{\mathrm{Sf}}\right)$ are initial stiffness $\left((\mathrm{d} \tau / \mathrm{d} \varepsilon)_{\mathrm{i}}\right)$, maximum stiffness $\left((\mathrm{d} \tau / \mathrm{d} \varepsilon)_{\max }\right)$, tensile shear strength $\left(\tau_{\mathrm{B}}\right)$, its strain $\left(\varepsilon_{\mathrm{B}}\right)$ and fracture strain $\left(\varepsilon_{\mathrm{Sf}}\right)$, which are employed here to quantitatively analyze our experimental values by the following equation: ${ }^{23)}$

$$
P=(I-0.3) /(n+0.4)
$$

Here, $n$ and $I$ are total number of samples $(n=11)$ and rank order of each sample from weakest to strongest $(1<I<11)$, respectively. When the $I$ values are 1, 6 and 11, the $P_{\mathrm{i}}$ values are $0.06,0.50$ and 0.94 , respectively.

\subsection{X-ray photoelectron spectrometry (XPS)}

To determine if the epoxy adhered well to the $18-8$ stainless steel, fracture surface analysis was carried out by X-ray photoelectron spectrometry (XPS: Quantum 2000, ULVAC Co., JAPAN).

\section{Results}

Figure 2 shows applying either 0.13 or 0.30 MGy HLEBI dose apparently improves the tensile shear strength, $\tau_{\mathrm{B}}$ of the $18-8 /$ CFRP joint $58 \%$ from 4.00 to $6.31 \mathrm{MPa}$ at medianaccumulative probability for tensile shear strength $P_{\mathrm{B}}=0.50$. Moreover, for both the 0.13 and $0.30 \mathrm{MGy}$ data sets $\tau_{\mathrm{B}}$ was improved substantially at each accumulative probability $P_{\mathrm{B}}$. However, the $0.13 \mathrm{MGy}$ HLEBI appears to be at or near the optimum since the higher dose of $0.30 \mathrm{MGy}-\mathrm{HLEBI}$ decays the $\tau_{\mathrm{B}}$ at low $P_{\mathrm{B}}<\sim 0.10$ as typical radiation damage although higher than that of the untreated. This indicates carefulness is extremely necessary when optimizing HLEBI dose in industry to maximize safety. 


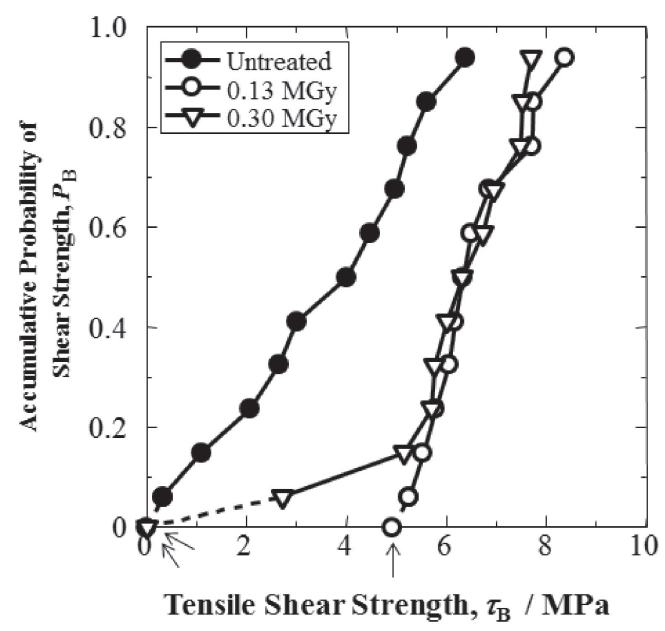

Fig. 2 Changes in maximum tensile shear strength $\left(\tau_{\mathrm{B}}\right)$ against maximum shear strength accumulative probability $\left(P_{\mathrm{B}}\right)$ of untreated and HLEBItreated 18-8/CFRP lamination joint specimens along with statistically lowest $\tau_{\mathrm{B}}$ values $\left(\tau_{\mathrm{s}}\right)$ at $P_{\mathrm{B}}=0$ (arrows) described in Section 4.1.

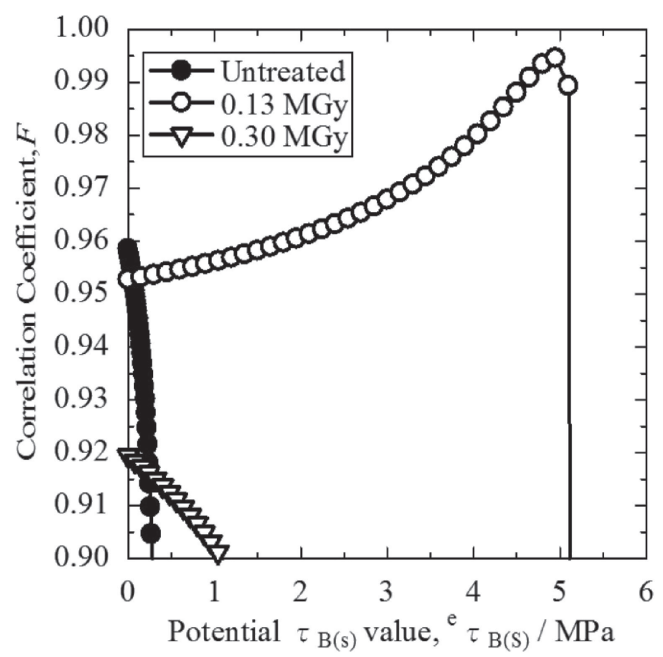

Fig. 3 Changes in correlation coefficient $(F)$ of eq. (3) against the potential $\tau_{\mathrm{s}}$ value $\left({ }^{\mathrm{e}} \tau_{\mathrm{s}}\right.$ ) for the untreated, 0.13 and $0.30 \mathrm{MGy}$ HLEBI $18-8 / \mathrm{CFRP}$ adhesion joints.

\section{Discussion}

\subsection{The statistically lowest tensile shear strength, $\tau_{\mathrm{s}}$ at $\boldsymbol{P}_{\mathrm{B}}=\mathbf{0}$ for safety}

To obtain statistically lowest $\tau_{\mathrm{B}}$ values $\left(\tau_{\mathrm{S}}\right)$ at $P_{\mathrm{B}}=0$ in Fig. 3 the 3-dimensional Weibull equation often used in quality control is employed. Hence, the relation in eq. (2) is applicable to the measured $\tau_{\mathrm{B}}$ values where the $P_{\mathrm{B}}$ values depend on the risk of rupture $\left(\left[\tau_{\mathrm{B}}-\tau_{\mathrm{S}}\right] / \tau_{\mathrm{III}}\right){ }^{12,19-21,25,27,28)}$

$$
P_{\mathrm{B}}=1-\exp \left[-\left(\left[\tau_{\mathrm{B}}-\tau_{\mathrm{S}}\right] / \tau_{I I I}\right)^{m}\right]
$$

The linear relationship can be converted from eq. (2), as follows.

$$
\ln \left(-\ln \left(1-P_{\mathrm{B}}\right)=m \ln \left(\left[\tau_{\mathrm{B}}-\tau_{\mathrm{S}}\right] / \tau_{\mathrm{III}}\right)\right.
$$

In predicting the $\tau_{\mathrm{s}}$, coefficient $(m)$ and constant $\left(\tau_{\mathrm{III}}\right)$ are the key paramters. When the term $\ln \left[-\ln \left(1-P_{\mathrm{p}}\right)\right]$ is zero, $P_{\mathrm{B}}$ is 0.632 and $\left(\tau_{\mathrm{B}}-\tau_{\mathrm{S}}\right)=\tau_{\mathrm{III}}$. The $\tau_{\mathrm{III}}$ value is determined, when the $\tau_{\mathrm{B}}$ value at $P_{\mathrm{B}}=0.632\left({ }^{\circ} F_{\mathrm{p}}(0.632)\right)$ is equal to $\left(\tau_{\mathrm{III}}+\tau_{\mathrm{s}}\right)$ value. When $P_{\mathrm{B}}=0$, the required $\tau_{\mathrm{B}}$ value to evaluate new

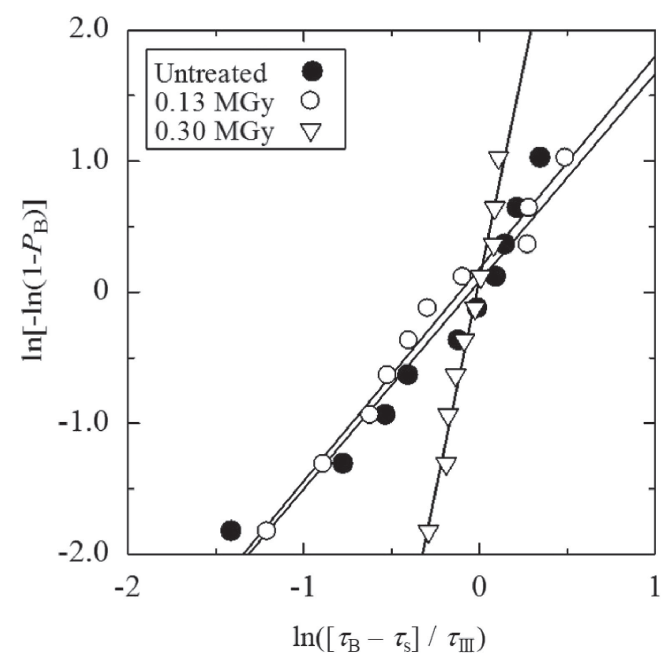

Fig. 4 Liner relationships between $\ln \left[-\ln \left(1-P_{\mathrm{B}}\right)\right]$ and $\ln \left(\left[\tau_{\mathrm{B}}-\tau_{\mathrm{s}}\right] / \tau_{\mathrm{III}}\right)$ for the untreated, 0.13 and $0.30 \mathrm{MGy}$ HLEBI 18-8/CFRP adhesion joints.

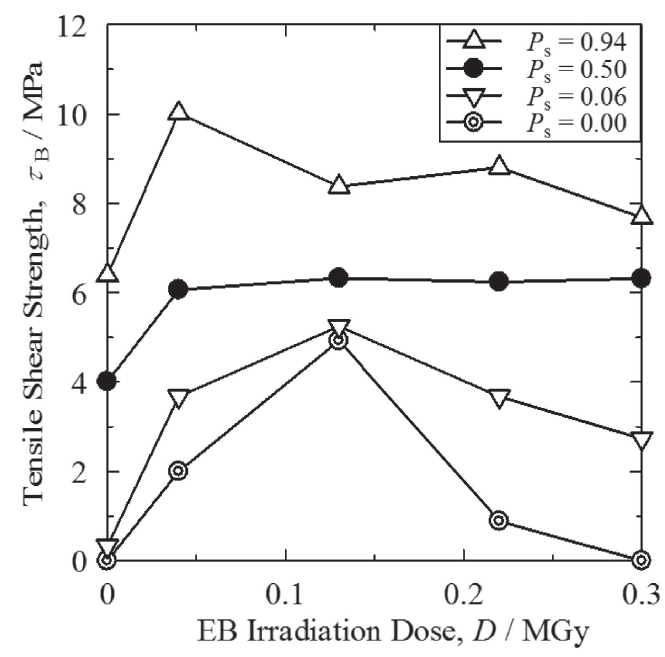

Fig. 5 Changes in tensile shear strength $\left(\tau_{\mathrm{B}}\right)$ at each shear strength accumulative probability $\left(P_{\mathrm{B}}\right)$ and $\tau_{\mathrm{s}}$ at $P_{\mathrm{B}}=0$ of $18-8 / \mathrm{CFRP}$ lamination joints against each dose.

structural materials is defined as the $\tau_{\mathrm{s}}$. Figure 3 illustrates plots the iteration to obtain the highest correlation coefficient $(F)$ with respect to the potential $\tau_{\mathrm{B}}$ value $\left({ }^{e} \tau_{\mathrm{s}}\right)$ estimated from the logarithmic form eq. (3). Figure 4 shows the linear relationships between $\ln \left(\left[\tau_{\mathrm{B}}-\tau_{\mathrm{s}}\right] / \tau_{\mathrm{III}}\right)$ and $\ln \left[-\ln \left(1-P_{\mathrm{B}}\right)\right]$. The values of $\tau_{\text {III }}$ and $m$ are determined by the least-squares best fit method. The $m$ value is estimated by the slope of the relationship when ${ }^{e} \tau_{\mathrm{s}}=\tau_{\mathrm{s}}$. Figure 3 shows applying the $0.13 \mathrm{MGy}$ HLEBI resulted in the highest $\tau_{\mathrm{s}}$ at $4.93 \mathrm{MPa}$ compared with zero $\mathrm{MPa}$ for the untreated and 0.30 MGy samples. Moreover, Fig. 3 shows the $0.13 \mathrm{MGy}$ data set has the highest correlation coefficient $F$ at 0.995 . The resulting linear relationships, $\ln \left(\left[\tau_{\mathrm{B}}-\tau_{\mathrm{S}}\right] / \tau_{\mathrm{III}}\right)$ vs. $\ln \left[-\ln \left(1-P_{\mathrm{S}}\right)\right]$ using the iterated $\tau_{\mathrm{s}}$ are illustrated in Fig. 4 showing the 0.13 MGy samples also had the highest slope, $m$.

Figure 5 shows HLEBI dose, $D$ vs. $\tau_{\mathrm{B}}$ at different $P_{\mathrm{B}}$. Notably, for $P_{\mathrm{B}}=0$, an increasing trend in $\tau_{\mathrm{s}}$ occurs up to $0.13 \mathrm{MGy}-\mathrm{HLEBI}$ reaching the maximum at $4.93 \mathrm{MPa}$, showing that improvement in safety level without radiation damage of the $18-8 /$ CFRP joint is possible. 


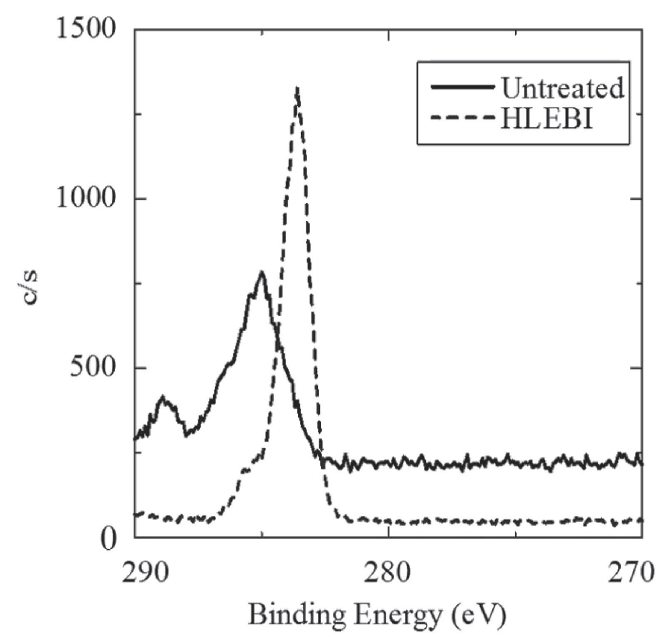

Fig. 6 Carbon (1s) signal in 18-8 fracture surface of XPS analysis of 18-8/ CFRP laminated joint with and without HLEBI prior to hot-pressing after lamination assembly.

This shows HLEBI induced adhesion can be applied to practical items with sterilization without volatilization, when the tensile shear strength is less than $4.93 \mathrm{MPa}$.

Figure 5 shows for the small dose of $0.04 \mathrm{MGy}$ HLEBI, although the $\tau_{\mathrm{s}}$ was lower $(2.10 \mathrm{MPa})$ than that for the 0.13 MGy samples, the 0.04 MGy HLEBI was enhanced over the untreated $\tau_{\mathrm{S}}$ and the $\tau_{\mathrm{B}}$ across the $P_{\mathrm{B}}$ range of $0.06,0.50$ and 0.94 .

\subsection{X-ray photoelectron spectrometry (XPS) of 18-8 Steel Surface}

Fracture surface analysis by X-ray photoelectron spectrometry (XPS) shown in Fig. 6 indicates that the HLEBI acts to produce strong adhesion in the $18-8 /$ CFRP lamination joint where fracture generally occurred at the shear-fractured 18-8-CFRP interface. Figure 6 illustrates the carbon (1s) signal detected from the 18-8 surface by XPS surface analysis with and without HLEBI treatment at binding energies of 276.5 and $274.5 \mathrm{eV}$, respectively. The higher intensity peak for the HLEBI treated specimen at $276.5 \mathrm{eV}$ indicates excess residual carbon adhered to the 18-8 interface from the epoxy increasing the adhesive force.

The epoxy in CFRP is composed of hydrogen $(\mathrm{H})$, carbon $(\mathrm{C})$, nitrogen $(\mathrm{N})$ and Oxygen $(\mathrm{O})$. When HLEBI creates increased adhesion at 18-8/CFRP interface, residual epoxy deposition in the form of increased intensity $\mathrm{C}(1 \mathrm{~s})$ peak is found to be retained on the $18-8$ sheet by inter-matrix fracture of epoxy resin further into the CFRP thickness near the carbon fibers. This can be explained by the adhesion force of 18-8/CFRP being stronger than the cohesive force of epoxy polymer in the CFRP itself.

By applying the HLEBI, electrons probably undergo polarization and bond or exhibit intermolecular coulomb attractive forces with the carbon fiber or 18-8 stainless steel making the $18-8 /$ CFRP bond stronger increasing the $\tau_{\mathrm{B}}$ and $\varepsilon_{\mathrm{S}}$ of the joint.

\subsection{Dangling bond effects and electron spin resonance (ESR)}

ESR is utilized to detect unpaired electrons, i.e. dangling bonds by their spins $\left(m_{\mathrm{s}}=+/-1 / 2\right)$ since electrons have

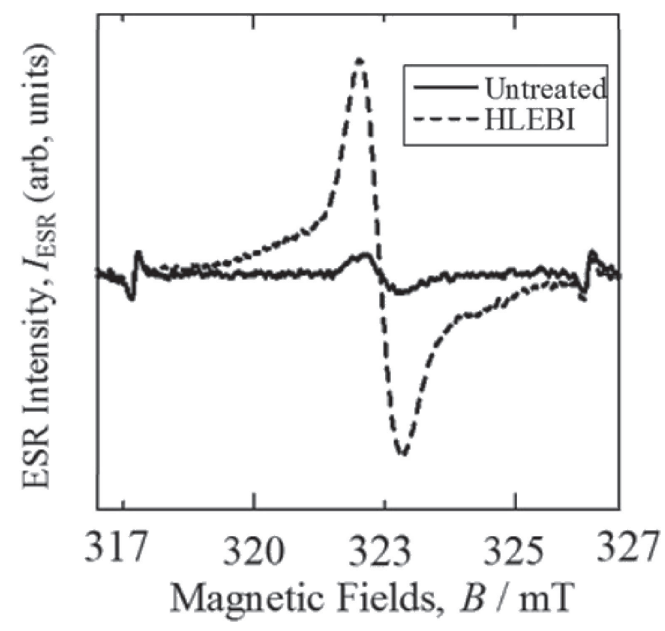

Fig. 7 ESR signals of epoxy polymer without carbon fibers before and after 0.13 MGy-HLEBI.

a magnetic moment and spin quantum number. When electrons are unpaired, their magnetic moments either align themselves parallel or anti-parallel to an induced magnetic field producing a peak at a particular magnetic field, $B$.

Figure 7 shows a strong ESR signal is generated in epoxy resin without carbon fibers by 0.13 MGy HLEBI whose inflection point occurs at $B=\sim 323.0 \mathrm{mT}$. However, experimental results showed epoxy containing carbon fibers (CFRP) did not generate an ESR signal. This is probably because while HLEBI generates or increases ESR signal intensity in epoxy, it is reported to decrease ESR signal intensity in carbon fibers. In untreated carbon fiber spontaneous vacant sites with dangling bonds generally exist as evidenced by a high intensity ESR peak at $B=\sim 322.4 \mathrm{mT}$ with measured dangling bond density by ESR of $1.2 \times 10^{17}$ spins $\mathrm{mm}^{-3}{ }^{32)}$ Applying $0.43 \mathrm{MGy}$ dose of HLEBI has been found to decrease the carbon fiber dangling bond density as evidenced by reduction in peak intensity at $B=\sim 322.4$ $\mathrm{mT}^{33)}$ It is assumed lower doses of 0.13 to $0.30 \mathrm{MGy}$ in this work also decrease dangling bond density in carbon fiber. This annihilation of vacant sites with dangling bonds of carbon fiber has been found to enhance the tensile fracture strength and its strain of carbon fiber. ${ }^{34-36)}$

The resulting charge difference due to dangling bond density gradient between the epoxy matrix and carbon fiber may cause electrons to migrate between the carbon fiber and epoxy matrix within the CFRP as they are energized maintaining an overall charge that enhances strength and fiber/matrix coupling undetectable by the ESR in the composite. This phenomenon is similar to that reported for PEEK (polyetheretherketone) CFRP composites where HLEBI generates a signal in PEEK resin but not in PEEK CFRP attributed to possible charge migration. ${ }^{33)}$ Moreover, in the $18-8 /$ CFRP joint dangling bonds may interact with the highly conductive $18-8$ steel by charge dispersion rendering undetectable by ESR yet strengthening the joint.

\section{Conclusions}

Up to now, adhesion of 2-layer laminated 18-8/CFRP sheets without our treatment of homogeneous low energy 
electron beam irradiation (HLEBI) prior to lamination assembly and hot-pressing has not been observed in the literature. However, strong adhesion of the 18-8/CFRP was created from the new treatment applying low dose $\leqq$ 0.30 MGy-HLEBI to the connecting surfaces of CFRP and 18-8 prior to lamination assembly and hot-pressing in vacuum below $1 \mathrm{~Pa}$ for $2 \mathrm{hr}$ at $401 \pm 0.5 \mathrm{~K}$.

(1) Although untreated 18-8/CFRP joint exhibited decent adhesion by hot-pressing, application of either 0.13 or $0.30 \mathrm{MGy}$ HLEBI dose apparently improved the tensile shear strength, $\tau_{\mathrm{B}}$ of the $18-8 / \mathrm{CFRP}$ joint $58 \%$ at median accumulative probability $\left(P_{\mathrm{B}}=0.50\right)$ from 4.0 to $6.3 \mathrm{MPa}$.

(2) In addition, HLEBI from 0.13 and 0.30 MGy was found to enhance the $\tau_{\mathrm{B}}$ at all $P_{\mathrm{B}}$.

(3) Also, based on the 3-parameter Weibull equation, the statistically lowest $\tau_{\mathrm{B}}$ value at $P_{\mathrm{B}}=0\left(\tau_{\mathrm{s}}\right)$ was increased from zero to $4.39 \mathrm{MPa}$ by applying the $0.13 \mathrm{MGy}$ HLEBI, indicating additive safety level increase in $\tau_{\mathrm{s}}$ as HLEBI dose is increased from 0 to $0.13 \mathrm{MGy}$, although the maximum $\tau_{\mathrm{s}}$ appears to drop off with $0.30 \mathrm{MGy}$ HLEBI as usual radiation damage.

(4) Surface analysis by XPS detected carbon on the shear fractured 18-8 interface indicating the residual epoxy adhered well to the $18-8$ by the HLEBI. In comparison, a smaller signal was observed in the untreated sample, laminated by hot-pressing but not HLEBI treated. The increased peak intensity is probably a result of adhesion force of $18-8 /$ CFRP being made stronger than the cohesive force of epoxy polymer in the CFRP itself by the HLEBI.

(5) A strong ESR signal was generated in epoxy resin without carbon fibers by $0.13 \mathrm{MGy}$ HLEBI whose inflection point occurred at $B=\sim 323.0 \mathrm{mT}$. However, experimental results showed epoxy containing carbon fibers (CFRP) did not generate an ESR signal. The resulting charge difference due to dangling bond density gradient between the epoxy matrix and carbon fiber probably caused electrons to migrate between the carbon fiber and epoxy matrix within the CFRP as they were energized maintaining an overall charge that enhances tensile shear strength and its strain of the joint and fiber/ matrix coupling in the CFRP undetectable by the ESR.

(6) In designing the adhesive lamination joint of 18-8 austenite stainless steel and CFRP carefulness must be considered to optimize the HLEBI dose since $0.13 \mathrm{MGy}$ appears to be at or near the optimum for high tensile shear strength, $\tau_{\mathrm{B}}$ and fracture strain $\varepsilon_{\mathrm{S}}$. If HLEBI dose is too high, $\tau_{\mathrm{B}}$ and $\varepsilon_{\mathrm{S}}$ are reduced. Therefore, with cautious consideration to optimize HLEBI dose level in industry for maximum safety, the new treatment applying HLEBI prior to lamination assembly and hot-pressing proves a viable method for quick lamination of 18-8 and epoxy CFRP to obtain the $18-8 /$ CFRP joint without the use of external adhesive or fasteners.

\section{Acknowledgements}

The authors thank Prof. Akira Tonegawa of Tokai University for his useful help. Our sincere gratitude also goes to Eye Electron Beam Co, Ltd. (Gyoda, Saitama, Japan) for their support with this work.

This work was partly supported by the Japan Science and Technology Agency (JST) A-STEP Program.

\section{REFERENCES}

1) D. K. Thomas: Plast. Rubber Int. 8 (1983) 53-57.

2) M. B. Dowell: Plast. Eng. 33 (1977) 31-32.

3) R. Matsuzaki, M. Shibata and A. Todoroki: Compos. Part A 39 (2008) 786-795.

4) R. Zitoune and F. Collombet: Compos. Part A 38 (2007) 858-866.

5) J. Paulo Davim, P. Reis and C. Couceição Antonio: Compos. Sci. Technol. 64 (2004) 289-297.

6) R. Matsuzaki, M. Shibata and A. Todoroki: Compos. Part A 39 (2008) 154-163.

7) K. Allen: Int. J. Adhes. 23 (2003) 87-93.

8) K. Oguri, N. Iwataka, A. Tonegawa, Y. Hirose, K. Takayama and Y. Nishi: J. Mater. Res. 16 (2001) 553-557.

9) K. Oguri, Y. Irisawa, A. Tonegawa and Y. Nishi: J. Intell. Mater. Struct. 17 (2006) 761-765.

10) K. Oguri, K. Fujita, M. Takahashi, Y. Omori, A. Tonegawa, N. Honda, M. Ochi, K. Takayama and Y. Nishi: J. Mater. Res. 13 (1998) 33683371.

11) K. Oguri, T. Takahashi, A. Kadowaki, A. Tonegawa and Y. Nishi: J. Japan Inst. Metals 68 (2004) 537-539.

12) Y. Nishi, H. Kobayashi and M. Salvia: Mater. Trans. 48 (2007) 19241927.

13) M. C. Faudree and Y. Nishi: Mater. Trans. 53 (2012) 1412-1419.

14) M. Kanda, Y. Miyazawa, M. Uyama and Y. Nishi: Mater. Trans. 54 (2013) 1795-1799

15) M. Uyama, N. Fujiyama, T. Okada, M. Kanda and Y. Nishi: Mater. Trans. 55 (2014) 561-565.

16) Y. Nishi, M. Uyama, H. Kawazu, H. Takei, K. Iwata, H. Kudoh and K. Mitsubayashi: Mater. Trans. 53 (2012) 1657-1664.

17) T. Shimaru: Technol. Adhes. Seal. 3 (1959) 121-130.

18) A. Kasashima, N. Iwataka, J. Kawano, N. Honda and Y. Nishi: J. Adv. Sci. 9 (1997) 70-71.

19) Y. Nishi, H. Sato, H. Takei and K. Iwata: J. Mater. Res. 24 (2009) 3503-3509.

20) H. Sato, K. Iwata, A. Tonegawa and Y. Nishi: J. Japan Inst. Metals 72 (2008) 526-531.

21) Y. Nishi, M. Uyama, H. Kawazu, H. Takei, K. Iwata, H. Kudoh and K. Mitsubayashi: Mater. Trans. 53 (2012) 1657-1664.

22) R. Christenhusz and L. Reimer: Z. Angew. Phys. 23 (1967) 396-404.

23) Y. Miyazawa, M. Uyama, S. Ishii, M. Kanda and Y. Nishi: Mater. Trans. 54 (2013) 1166-1170.

24) T. Nishida and E. Yasuda: Evaluation of Dynamic Properties of Ceramics (in Japanese: Ceramics no rikigaku tokusei hyouka), (Nikkan Kogyou Shimbun Sha, Tokyo, 1986) pp. 50-51.

25) H. Takei, M. Salvia, A. Vautrin, A. Tonegawa and Y. Nishi: Mater. Trans. 52 (2011) 734-739.

26) M. Kanda and Y. Nishi: Mater. Trans. 50 (2009) 177-181.

27) K. Iwata and Y. Nishi: Mater. Trans. 49 (2008) 2058-2062.

28) K. Iwata and Y. Nishi: Mater. Trans. 51 (2010) 121-127.

29) N. Tsuchikura, M. C. Faudree and Y. Nishi: Mater. Trans. 54 (2013) 371-379.

30) Y. Nishi, H. Takei, K. Iwata, M. Salvia and A. Vautrin: Mater. Trans. 50 (2009) 2826-2832.

31) H. Takei, K. Iwata, M. Salvia, A. Vautrin and Y. Nishi: Mater. Trans. 51 (2010) 2259-2265.

32) Y. Nishi, H. Takei, K. Iwata, M. Salvia and A. Vautrin: Mater. Trans. 50 (2009) 2826-2832.

33) Y. Nishi, R. Ourahmoune, M. Kanda, J. Quan, M. C. Faudree and M. Salvia: Mater. Trans. 55 (2014) 1304-1310.

34) Y. Nishi, T. Toriyama, K. Oguri, A. Tonegawa and K. Takayama: J. Mater. Res. 16 (2001) 1632-1635.

35) Y. Nishi, A. Mizutani, A. Kimura, T. Toriyama, K. Oguri and A. Tonegawa: J. Mater. Sci. 38 (2003) 2215-2218.

36) Y. Nishi, A. Mizutani and N. Uchida: J. Thermoplast. Compos. Mater. 17 (2004) 289-302. 